\title{
Factors related to intentional and unintentional medication nonadherence in elderly patients with hypertension in rural community
}

This article was published in the following Dove Press journal:

Patient Preference and Adherence

29 September 2016

Number of times this article has been viewed

\author{
Sang Geun Bae,' Sin Kam, ${ }^{2}$ \\ Ki Soo Park, ${ }^{3,4}$ Keon-Yeop \\ Kim, ${ }^{2}$ Nam-Soo Hong, ${ }^{2}$ \\ $\mathrm{Ki}-\mathrm{Su} \mathrm{Kim},{ }^{2}$ Yu-mi Lee, ${ }^{2}$ \\ Won Kee Lee, ${ }^{2}$ Michael \\ Sung Pil Choe ${ }^{5}$ \\ 'Department of Preventive Medicine, \\ Regional Cardiocerebrovascular \\ Disease Center, Kyungpook National \\ University Hospital, ${ }^{2}$ Department \\ of Preventive Medicine, Kyungpook \\ National University School \\ of Medicine, Daegu, ${ }^{3}$ Department of \\ Preventive Medicine and Institute of \\ Health Sciences, Gyeongsang National \\ University School of Medicine, \\ ${ }^{4}$ Department of Preventive Medicine, \\ Regional Cardiocerebrovascular \\ Disease Center, Gyeongsang \\ National University Hospital, Jinju, \\ ${ }^{5}$ Department of Emergency Medicine, \\ CHA Gumi Medical Center, CHA \\ University, Gumi, Korea
}

Correspondence: Michael Sung Pil Choe Department of Emergency Medicine,

CHA Gumi Medical Center, CHA

University, 10, Sinsi-ro,

Gumi-si 39315, Korea

$\mathrm{Tel}+8254$ I0 970709 । ।

Fax +82 547078170139

Email michaelchoemd@gmail.com

Ki Soo Park

Department of Preventive Medicine and Institute of Health Sciences, Gyeongsang National University School of Medicine, I5 Jinju-daero, 816 Beon-gil,

Jinju 52727, Korea

Tel +82 557728095

Fax+82557728099

Email parkks@gnu.ac.kr
Purpose: We assessed medication nonadherence, categorized as intentional or unintentional, and related factors in elderly patients with hypertension, correlating the data with measurement of blood pressure as the final target of medication adherence and other possible influencing factors, such as lifestyle.

Patients and methods: Subjects were aged $\geq 65$ years, resided in a rural area, and were taking antihypertensive drugs. The survey was conducted in July 2014. Participants were divided into the following three groups: "Adherence", "Unintentional nonadherence", and "Intentional nonadherence". Individual cognitive components, such as necessity and concern as well as self-efficacy and other related factors, were compared according to adherence groups. The interrelationships between those factors and nonadherence were tested using structural equation modeling analysis.

Results: Of the 401 subjects, 182 (45.6\%) were in the adherence group, 107 (26.7\%) in the unintentional nonadherence group, and $112(27.9 \%)$ in the intentional nonadherence group. Necessity and self-efficacy were found to have a significant direct influence on unintentional nonadherence behaviors (necessity $\beta=-0.171, P=0.019$; self-efficacy $\beta=-0.433, P<0.001$ ); concern was not statistically significant $(\beta=-0.009, P=0.909)$. Necessity was found to have significant direct and indirect impact on intentional nonadherence (direct $\beta=-0.275, P=0.002$; indirect $\beta=-0.113$, $P=0.036$ ). Self-efficacy had no significant direct effect on intentional nonadherence though it had the only significant indirect effect on intentional nonadherence (direct $\beta=-0.055, P=0.515$; indirect $\beta=-0.286, P<0.001)$. Concern had no significant influence on intentional or on unintentional nonadherence (direct $\beta=0.1320 .132, P=0.151$; indirect $\beta=-0.006, P=0.909$ ).

Conclusion: Unintentional nonadherence should be regularly monitored and managed because of its potential prognostic significance. Interventions addressing cognitive factors, such as beliefs about medicine or self-efficacy, are relatively difficult to implement, but are essential to improve medication adherence.

Keywords: medication adherence, hypertension, aged, self-control, self-efficacy

\section{Introduction}

Hypertension is one of the most important risk factors for cardiovascular disease and stroke. With lifestyle modification, medication is considered essential in the treatment of persistent hypertension. ${ }^{1}$ Meta-analyses have revealed that adherence to prescribed medication is related to control of hypertension and a lower death rate. ${ }^{2,3}$ However, in 2013, in Korea, a national health and nutrition survey ${ }^{4}$ found that only $\sim 60 \%$ of patients took medication prescribed for hypertension regularly and $\sim 40 \%$ of patients achieved optimum blood pressure. Since the mid-2000s, the rates of adherence and blood pressure control in hypertensive patients have not improved in Korea. 
The World Health Organization classified the improvement of medication adherence as a key factor for the successful management of major chronic diseases. ${ }^{5}$ Measures to improve adherence are widely acknowledged to be a primary intervention. ${ }^{6}$

Medication nonadherence can be often classified as intentional or unintentional according to the patient's perspective. ${ }^{7-12}$ Intentional nonadherence is considered a process in which the patient actively decides not to take medication or follow treatment recommendations, presumably having weighed the costs and benefits of treatment. Unintentional nonadherence refers to unplanned behavior; it is passive rather than active and is sometimes due to factors beyond the patient's control. This classification has significant implications for health professionals in that it offers a framework to understand medication-taking behaviors and consequently impacts the type of intervention chosen to improve adherence. ${ }^{9}$

Intentional nonadherence is driven by the patient's knowledge, motivation, or beliefs about illness or treatment. Unintentional nonadherence is reportedly more related to demographic factors, particularly age, rather than the individual's knowledge or beliefs. ${ }^{8,13}$ However, recent studies indicate that unintentional nonadherence is significantly affected by beliefs about illness and medication or self-efficacy. ${ }^{8,9}$ A study in American patients with chronic disease revealed that unintentional nonadherence was somewhat predictable depending on beliefs and concerns about medicines. ${ }^{13}$ Although some studies have shown that there is an overlap between the two types of nonadherence behaviors, ${ }^{9,13,14}$ understanding of the interrelationship between intentional and unintentional nonadherence is still insufficient.

In the self-regulatory model, adherence to medication is considered one of the numerous measures that patients can adopt to deal with the threat of their illness. In this model, adherence is more likely if it makes sense within the individual's concept of the illness. It is a response to one's cognitive and emotional interpretation of past experiences or information. ${ }^{15}$ Based on self-regulatory model, Horne et al ${ }^{16}$ developed the Beliefs about Medicines Questionnaire (BMQ), expecting that beliefs about medications are more strongly associated with treatment adherence than are beliefs about the illness itself. BMQ evaluates the individual's perception of the necessity for and beneficial effects of treatment and concerns about harmful effects and developing dependence. In other words, it addresses the individual's benefits (necessity) and costs (concern) of treatment. The validity of BMQ in assessing medication adherence has been demonstrated in various diseases and populations. ${ }^{16,17}$
Self-efficacy is defined as personal confidence of performance ability of proceeding a specific task to achieve the desired goal, which is known to influence initiation and persistence of health behavior. ${ }^{18}$ Self-efficacy directly influences medication adherence but also mediates effect of cognitive and emotional factors, including depression and social support, which in turn influences medication adherence. ${ }^{19,20} \mathrm{We}$ have limited understanding of self-efficacy when nonadherence of medication is separated into intentional and unintentional.

Patients with high medication adherence show a higher quality of other lifestyle, known as the "health adherer effect". Simpson et $\mathrm{al}^{2}$ reported that patients with higher medication adherence showed lower mortality rate even in the placebo group. The association of intentional or unintentional medication adherence to lifestyle is not clear.

In this study, we assessed medication nonadherence, categorized as intentional or unintentional, and related factors in elderly patients with hypertension, correlating the data with measurement of blood pressure as the final target of medication adherence and other possible influencing factors, such as lifestyle. We intended to examine the effects of individual cognitive factors, such as beliefs about medicines and self-efficacy on medication adherence in control of hypertension.

\section{Patients and methods Study subjects}

The study was conducted in a rural community. Subjects were eligible for participation if they were aged $\geq 65$ years, resided in the rural area, and were taking antihypertensive drugs. The survey was conducted in July 2014. The interviewers were students in a medical school who were trained in measuring blood pressure and conducting the survey. The institutional review board of Gyeongsang national university hospital approved the study.

The interviewers visited the area and asked elderly residents whether or not they were taking blood pressure drugs and also measured their blood pressure. If they reported taking antihypertensives, the interviewers proceeded with the survey, filling a questionnaire in a one-on-one interview. All participants provided written informed consent prior to starting the survey. Subjects were excluded if they had severe chronic disease, such as angina, myocardial infarction, stroke, or cancer, that could affect adherence to medication or if they could not communicate with the interviewers. Data for 401 subjects who finished the survey were analyzed.

\section{Measures}

The study model is presented in Figure 1. Nonadherence was defined as intentional or unintentional. Intentional 


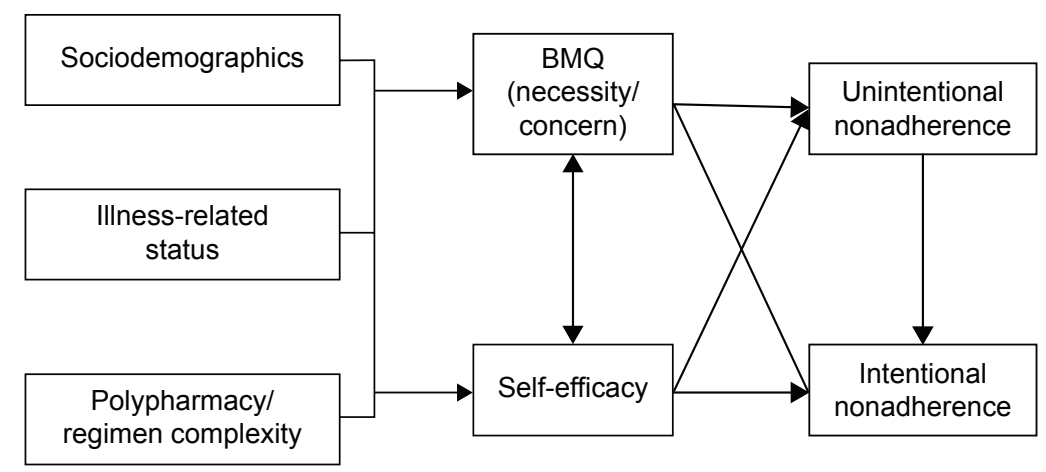

Figure I Framework of current study.

Abbreviation: BMQ, beliefs about medicines questionnaire.

nonadherence is an active decision not to take medication; hence, it was considered a final step of nonadherence. It was hypothesized that unintentional nonadherence affects intentional nonadherence. For example, patients with unintentional nonadherence may feel that their condition is not worsened when they forget to take the medicine, so they begin to doubt that the medication is actually effective. ${ }^{21-23}$ This doubt may then result in intentional nonadherence.

Assuming that individual cognitive components, such as necessity and concern as well as self-efficacy, are direct subjects of patient education and targets of interventions to improve adherence to medication, it was hypothesized that those components are the final determinants of medication adherence. Other factors known to affect adherence, such as sociodemographics, illness-related status, polypharmacy, and regimen complexity, are thought to affect the cognitive components.

Other factors known to affect adherence, such as sociodemographics, illness-related status, polypharmacy, and regimen complexity, are thought to affect the cognitive components but it was hypothesized that there is no control over these factors. Sociodemographics are determined genetically or socially and illness-related status and polypharmacy/regimen complexity are mostly determined by diagnosis and severity of patient condition. And these factors influence individual cognitive factors, including BMQ or self-efficacy, leading each individual patient to determine the medication adherence. Influences of sociodemographics, illness-related status, and polypharmacy/ regimen complexity to necessity/concern and self-efficacy were demonstrated using multiple regression analysis. And interrelationship of individual cognitive factors and medication nonadherence was only presented in structural equation modeling (SEM).

The survey included sociodemographic items, such as age, gender, education, monthly household income, and living with a spouse. Age was measured on a continuous scale, and gender was measured on a binary scale. Education was measured as a categorical variable with three categories ranging from less than or equal to primary school to more than or equal to high school. Monthly household income was also measured as a categorical variable with three categories ranging from "less than 1,000,000 Korean Won (KRW)" to "more than or equal to 2,000,000 KRW". Living with a spouse was measured on a binary scale as "yes" or "no".

Illness-related status and polypharmacy or regimen complexity-related variables were also surveyed, including drug count, medication frequency, duration of hypertension, comorbidity, and self-rated health status. Medication frequency was measured on a categorical scale with the following four categories: "once a day in the morning", "once a day at night", "twice a day in the morning and at night", and "thrice a day after every meal". Given the number of categories, medication frequency was treated in the final analysis as a binary variable categorized as "once a day" or "twice a day". The duration of hypertension was measured on a continuous scale, and comorbidity was reported as "yes" or "no". Self-rated health status was measured as a categorical variable with five categories, ranging from "very good" to "very poor". In the final analysis, these responses were combined into the following three categories: "good", "moderate", and "bad".

\section{Medication adherence}

The author used six "yes" or "no" questions, which were used in previous Korean research, to assess medication nonadherence. ${ }^{7}$ The items related to intentional nonadherence included "you felt worse when you took it", "you felt like your blood pressure is under control", and "you felt hassled about sticking to your blood pressure treatment plan". Those related to unintentional nonadherence included "you forget to take your high blood pressure drugs", "were there any days when 
you do not take your high blood pressure medicine over the past 2 weeks", and "you forget to carry your medications when you travel or leave home". These six items were examined for content validity by a professor of internal medicine and a professor of preventive medicine. Two factors were extracted in factor analysis, accounting for $67.3 \%$ of the variance. The factor loading of each item on intentional nonadherence and unintentional nonadherence ranged from 0.616 to 0.777 and from 0.612 to 0.983 , respectively. Cronbach's alpha was 0.563 and 0.694 , respectively. Participants were divided into the following three groups according to medication adherence: "adherence", in which they answered no for all six questions; "unintentional non-adherence", in which they answered no for all the three intentional nonadherence items, but answered yes for any of unintentional nonadherence items; and "intentional nonadherence," in which they answered yes for any of the three intentional non-adherence items.

\section{Beliefs about medicines questionnaire}

Beliefs about medication were measured using BMQ developed by Horne et al, ${ }^{16}$ which has been used in other Korean researches recently. ${ }^{7,24,25}$ Respondents answered ten questions that addressed necessity and concern, with each construct addressed by five items. A five-category ordered response set ranged from strongly agree (5) to strongly disagree (1). Two multiitem scales were created by summing responses to the raw items into a scale score, in which higher scores represented stronger beliefs. Cronbach's alpha coefficients for necessity and concern were 0.810 and 0.692 , respectively. Two factors were extracted in factor analysis, and they were the same constructs as those presented by Horne et al.

\section{Self-efficacy}

Self-efficacy was assessed using the Medication Adherence Self-efficacy Scale-Revision (MASES-R) developed by Fernandez et al. ${ }^{26}$ This is a 13 -item scale used to assess patients' confidence in their ability to manage their antihypertensive medications in various situations. Some examples include "when busy at home", "when there is no one to remind you", or "when you do not have any symptoms". The four-category ordered response set ranged from extremely sure (5) to not at all sure (1), and a multiitem construct was created by summing the 13 items into a score. Cronbach's alpha coefficient for MASES-R was 0.956 .

\section{Blood pressure}

Using a standard protocol, blood pressure was measured with a calibrated mercury sphygmomanometer and stethoscope.
The survey interview lasted for 20-30 minutes. After finishing the survey, the subjects rested for 5 minutes, after which the blood pressure was measured in the right arm with the subject seated. A second blood pressure reading was taken 5 minutes later. The mean of the two results was used in analyzing data. Blood pressure was considered to be uncontrolled if either the mean systolic pressure was $\geq 140 \mathrm{mmHg}$ or the mean diastolic pressure was $\geq 90 \mathrm{mmHg}$, according to the Eighth Joint National Committee recommendations. ${ }^{1}$

\section{Lifestyle}

Respondents answered six questions about lifestyle, including low-salt diet, low-fat diet, exercise, networking with other people, moderate drinking, and smoking. The five-category ordered response set ranged from always do (5) to never do (1), and the sum of the six items was used in the analysis.

The framework of the current study is presented in Figure 1.

\section{Analysis}

All variables were compared among the adherence, unintentional nonadherence, and intentional nonadherence groups. Analysis of variance was used for continuous variables, and chi-square tests were used for categorical variables. Blood pressure was also compared, according to adherence groups, using analysis of variance. Subjects were divided into two groups according to blood pressure control and compared using a chi-square test, and linear trend in proportions according to adherence groups was also tested using the chi-square test.

Multiple regression analysis was used to examine the relationship between medication adherence and lifestyle. Because lifestyle differed considerably according to gender, data were stratified by gender, and coefficients of unintentional nonadherence and intentional nonadherence groups were estimated as adjusted for sociodemographic, illness-related status, polypharmacy, and regimen complexity-related variables.

These factors were also examined for effect on BMQ and self-efficacy, using multiple regression analysis.

SEM was used to assess the effects of BMQ and selfefficacy on the two types of nonadherence and the interrelationship between unintentional and intentional nonadherence. The first SEM analysis investigated the impact of necessity, concern, and self-efficacy on unintentional adherence, and the second analysis looked at the effect of the same variables on intentional adherence. Because intentional adherence could be mediated by unintentional adherence, indirect effects were also considered. Because outcome variables were binary, we employed the robust, diagonally weighted 
least squares method. The goodness of fit was assessed by the likelihood ratio chi-square $\left(\chi^{2}\right)$, comparative fit index (CFI), Tucker-Lewis index (TLI), weighted root mean square residual (WRMR), and the root mean square error of approximation (RMSEA). ${ }^{27,28}$

\section{Results}

Of the 401 subjects (mean age 74.5 years) who participated in the survey, 303 (75.6\%) were female. A majority of participants had a monthly household income of $<1,000,000 \mathrm{KRW}$ $(331,82.5 \%)$ and less than elementary school $(335,83.5 \%)$ education. Of the total number of subjects, 188 (46.5\%) lived with their spouse. The mean time since diagnosis was 8.7 years, suggesting a relatively long period. Most participants took their medication only once a day $(367,91.5 \%)$. On an average, they were prescribed 3.1 medications, including drugs other than antihypertensive. Over one-half (229, $57.1 \%$ ) of them had other diseases besides hypertension, and $184(45.9 \%)$ rated their health as bad.
According to their self-report, $182(45.6 \%)$ of subjects were in the adherence group, 107 (26.7\%) in the unintentional nonadherence group, and $112(27.9 \%)$ in the intentional nonadherence group. Medication adherence significantly varied with household income, with respondents with a higher household income being more likely to be nonadherent $(P=0.038)$. Other illness-related or polypharmacy or regimen complexity-related variables were not significantly associated with medication adherence (Table 1).

The mean scores for necessity and concern were 16.5 and 12.4, respectively. The concern scores did not differ significantly among the groups $(P=0.441)$. The necessity scores of participants in the adherence group were higher than those in the intentional nonadherence group $(P=0.001)$, but not in the unintentional adherence group $(P=0.904)$. The mean score for self-efficacy was 39.3 and was significantly related to medication adherence $(P<0.001)$. Compared with the adherence group, both the nonadherence groups had lower self-efficacy $(P<0.001)$, but the two nonadherence groups

Table I General characteristics and medication adherence

\begin{tabular}{|c|c|c|c|c|}
\hline \multirow[t]{3}{*}{ Characteristic } & \multicolumn{3}{|c|}{ Medication adherence status } & \multirow[t]{3}{*}{$P$-value ${ }^{a}$} \\
\hline & \multirow[t]{2}{*}{ Adherence } & \multicolumn{2}{|l|}{ Nonadherence } & \\
\hline & & Unintentional & Intentional & \\
\hline Age (years) & $75.3 \pm 8.6$ & $74.4 \pm 8.5$ & $73.2 \pm 8.6$ & 0.110 \\
\hline Gender & & & & 0.132 \\
\hline Male & $4 I(4 I .8)$ & $22(22.4)$ & $35(35.7)$ & \\
\hline Female & |4| (46.5) & $85(28.1)$ & $77(25.4)$ & \\
\hline Educational level & & & & 0.056 \\
\hline$\leq$ Primary school & 159 (47.5) & $92(27.5)$ & $84(25.1)$ & \\
\hline Middle school & $16(39.0)$ & $9(22.0)$ & $16(39.0)$ & \\
\hline$\geq$ High school & $7(28.0)$ & $6(24.0)$ & $12(48.0)$ & \\
\hline Income & & & & 0.038 \\
\hline$<\mathrm{I}$ million $\mathrm{KRW}$ & $156(47.1)$ & $93(28.1)$ & $82(24.8)$ & \\
\hline $\mathrm{I}-2$ million $\mathrm{KRW}$ & $19(40.4)$ & $9(19.1)$ & $19(40.4)$ & \\
\hline$\geq 2$ million $\mathrm{KRW}$ & $7(30.4)$ & $5(21.7)$ & II (47.8) & \\
\hline Spouse & & & & 0.426 \\
\hline Yes & $80(42.6)$ & $50(26.6)$ & $58(30.9)$ & \\
\hline No & 102 (47.9) & $57(26.8)$ & $54(25.4)$ & \\
\hline Duration & $9.2 \pm 6.8$ & $8.7 \pm 8.1$ & $7.8 \pm 6.3$ & 0.275 \\
\hline Drug count & $3.0 \pm 2.1$ & $3.4 \pm 1.9$ & $2.9 \pm 1.7$ & 0.072 \\
\hline Medication frequency & & & & 0.676 \\
\hline Once a day & $169(46.0)$ & I0I (27.5) & $97(26.4)$ & \\
\hline Twice a day & $13(38.2)$ & $10(29.4)$ & II (32.4) & \\
\hline Comorbidity & & & & 0.958 \\
\hline Yes & $104(45.4)$ & $60(26.2)$ & $65(28.4)$ & \\
\hline No & $78(45.3)$ & $47(27.3)$ & $47(27.3)$ & \\
\hline Self-rated health & & & & 0.089 \\
\hline Good & $31(53.4)$ & $10(17.2)$ & $17(29.3)$ & \\
\hline Normal & $60(37.7)$ & $49(30.8)$ & $50(31.4)$ & \\
\hline Bad & $91(49.5)$ & $48(26.1)$ & $45(24.5)$ & \\
\hline Total & $182(45.4)$ & 107 (26.7) & I I2 (27.9) & \\
\hline
\end{tabular}

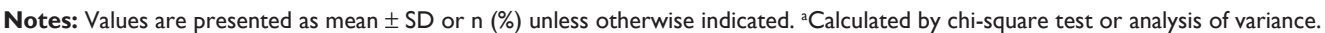
Abbreviations: SD, standard deviation; KRW, Korean Won. 
did not differ from one another on self-efficacy $(P=0.226)$ (Table 2).

Systolic blood pressures of patients in the adherence group $(130.5 \mathrm{mmHg})$ were lower than those of patients in the intentional nonadherence group $(135.6 \mathrm{mmHg}, P=0.003)$ but not in the unintentional nonadherence group $(131.5 \mathrm{mmHg}$, $P=0.771$ ). Diastolic blood pressure did not differ significantly between the three groups $(P=0.095)$ (Figure 2). The blood pressure control rates, the percentage of subjects attaining the target blood pressure, did not differ significantly between the groups (adherence $=47.3 \%$, unintentional nonadherence $=43.9 \%$, and intentional nonadherence group $=42.9 \%$ ). The linear trend of blood pressure control rate according to adherence groups was not significant $(P=0.466)$ (Table 3$)$.

After controlling for sociodemographics, illness-related factors, polypharmacy, and regimen complexity, the lifestyle scores in male respondents did not differ significantly among the three groups. In contrast, female respondents in the intentional nonadherence group had significantly lower lifestyle scores than those in the adherence group $(P=0.036)$ (Table 4).

Associations between sociodemographics, illnessrelated factors, polypharmacy/regimen complexity-related variables, social cognitive factors ascertained by BMQ, and self-efficacy assessment are presented in Table 5. None of the variables were significantly related to necessity and selfefficacy. However, concern scores of patients whose household income was $<1$ million KRW were higher than those of patients whose household income was 1-2 million KRW ( $P=0.048$ ), but did not differ from those of patients whose household income was $>2$ million KRW $(P=0.876)$.

The relationships between the social cognitive factors and self-efficacy and nonadherence were tested using SEM analysis. The results suggest that the model fits well with the data, presenting adequate fit indices: $\chi^{2}=122.644$, TLI $=0.972$, CFI $=0.903$, WRMR $=0.775$, and RMSEA $=0.045$.

Figure 3 depicts the standardized path coefficients and their significance, and Table 6 presents indirect effects of necessity, concern, and self-efficacy on intentional nonadherence mediated by unintentional nonadherence. Necessity and self-efficacy were found to have a significant direct influence on unintentional nonadherence behaviors (necessity $\beta=-0.171, P=0.019$; self-efficacy $\beta=-0.433, P<0.001$ ); concern was not statistically significant $(\beta=-0.009, P=0.909)$. Necessity was found to have significant direct and indirect impact on intentional adherence (direct $\beta=-0.275, P=0.002$; indirect $\beta=-0.113, P=0.036$ ). Self-efficacy had no significant direct effect on intentional nonadherence. The only significant indirect effect it had was on unintentional adherence (direct $\beta=-0.055, P=0.515$; indirect $\beta=-0.286, P<0.001$ ). Concern had no significant influence on intentional or on unintentional adherence (direct $\beta=0.132$ 0.132, $P=0.151$; indirect $\beta=-0.006, P=0.909$ ).

\section{Discussion}

In this study, medication adherence and its related factors in elderly hypertensive patients were assessed using a crosssectional survey design.

Self-report in such a survey is not a quantifiable measure of adherence, and it is also subject to recall bias and overestimation of adherence. ${ }^{29}$ However, in the outpatient setting or community-based programs, self-report is a very useful, efficient, and appropriate method to differentiate types of nonadherence and assess patients' knowledge or beliefs about medication. ${ }^{29,30}$ Only $45.4 \%$ of the elderly patients with hypertension in our study were adherent to their medication, indicating that improved adherence still needs to be addressed in the management of high blood pressure. The percentage of those who admitted to any of the unintentional nonadherence behaviors was $48.9 \%$, whereas $27.9 \%$ admitted to one or more of the intentional nonadherence behaviors. Thus, most of those in the intentional nonadherence group also had unintentional nonadherence behaviors, as has been reported by other groups, where unintentional and intentional nonadherence were in the proportion of two or three to one. ${ }^{11,13,31}$

Table 2 Beliefs about medication questionnaire (BMQ) and medication adherence

\begin{tabular}{|c|c|c|c|c|}
\hline \multirow[t]{3}{*}{ Individual cognitive factors } & \multicolumn{3}{|c|}{ Medication adherence status } & \multirow[t]{3}{*}{$P$-value ${ }^{a}$} \\
\hline & \multirow[t]{2}{*}{ Adherent (A) } & \multicolumn{2}{|l|}{ Nonadherent } & \\
\hline & & Unintentional (B) & Intentional (C) & \\
\hline BMQ (necessity) & $17.0 \pm 4.1$ & $16.8 \pm 3.3$ & $15.3 \pm 3.6$ & $0.001(A, B)(C)$ \\
\hline BMQ (concerns) & $12.2 \pm 3.5$ & $12.6 \pm 2.9$ & $12.6 \pm 3.2$ & $0.44 I$ \\
\hline Self-efficacy & $42.3 \pm 8.2$ & $37.9 \pm 7.3$ & $36.1 \pm 8.4$ & $<0.00 \mathrm{I}(\mathrm{A})(\mathrm{B}, \mathrm{C})$ \\
\hline
\end{tabular}

Notes: Values are presented as mean \pm SD unless otherwise indicated. ${ }^{2}$ Calculated by analysis of variance (Tukey multiple comparison).

Abbreviations: BMQ, beliefs about medicines questionnaire; SD, standard deviation. 


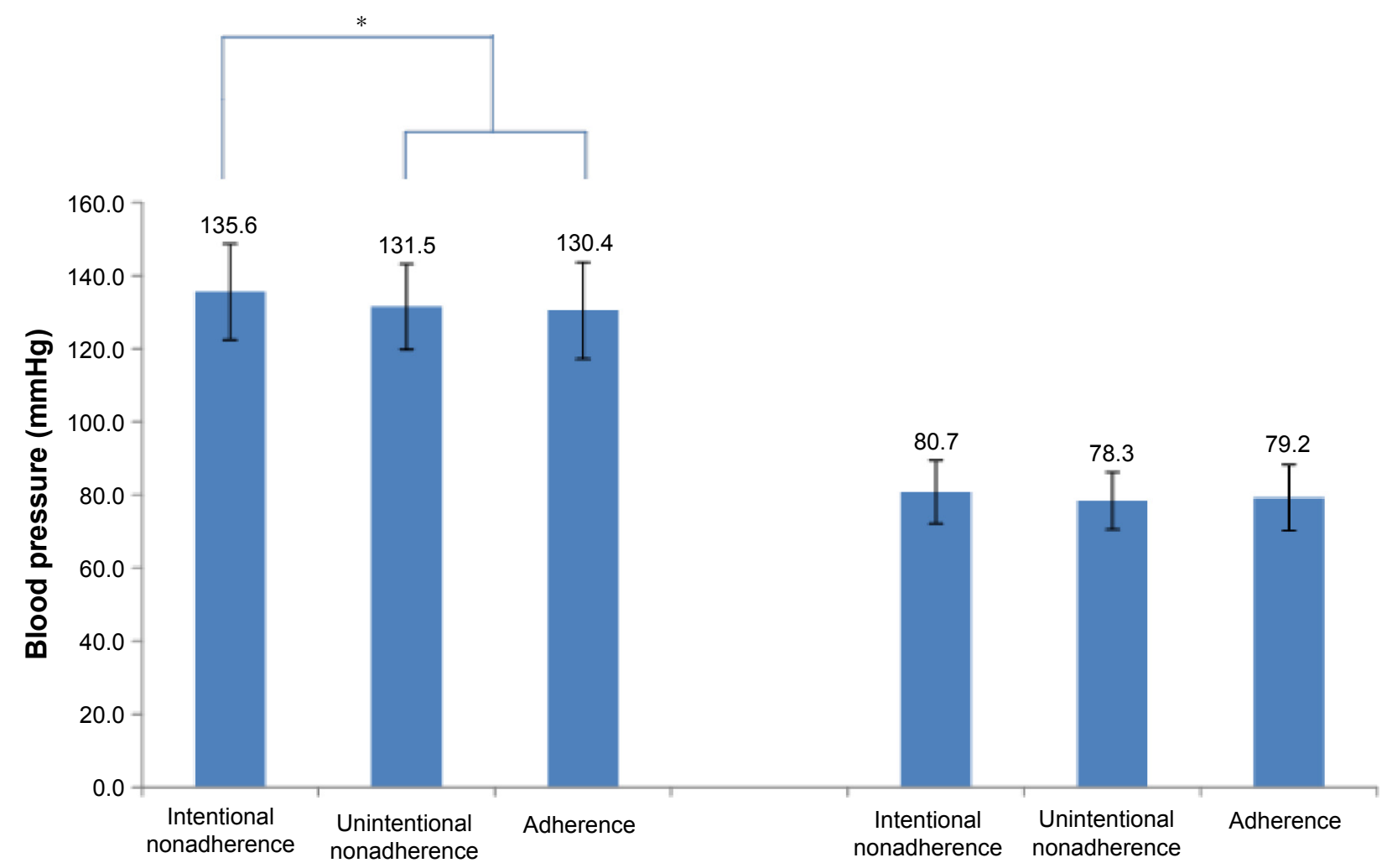

Figure 2 Blood pressure according to medication adherence groups. Left is systolic blood pressure and right is diastolic blood pressure. Note: $* P<0.05$.

Some studies have shown that patients' concepts of necessity or concern as well as self-efficacy are also related to unintentional nonadherence. ${ }^{9,13}$ In patients with chronic disease, perceived need, concern, and affordability affect intentional nonadherence, and they also affect unintentional nonadherence, such that the unintentional behavior is thought to mediate intentional nonadherence. ${ }^{13}$ In that study, unintentional and intentional nonadherence were found to be closely related, and unintentional nonadherence behaviors sometimes appeared to be a risk factor for intentional nonadherence. Others have suggested that during occasional episodes of unintentional nonadherence, patients may be testing a medication's effectiveness or assessing their symptom status without taking the medication. ${ }^{21-23}$ Some patients may also report unintentional nonadherence instead of intentional nonadherence because forgetfulness or carelessness is considered more socially acceptable than deliberately not taking medications. ${ }^{32}$

Self-efficacy is related to various health behaviors needed to manage chronic diseases ${ }^{33}$ and has been shown to be related to adherence to medication in patients with hypertension. ${ }^{26}$ In addition to a direct effect on medication adherence, it also mediated the effect of depression on adherence among patients with hypertension. ${ }^{19}$ Self-efficacy is reported to serve as a mediator in the relationship between depression, social support, and type D personality and medication adherence or clinical outcome in diabetes mellitus, human immunodeficiency virus, and acute coronary syndrome patients. ${ }^{20,34,35}$ Self-efficacy was known to have protective role and when people lack a sense of self-efficacy, they

Table 3 Relationship between blood pressure control and medication adherence

\begin{tabular}{|c|c|c|c|c|}
\hline \multirow[t]{2}{*}{ Medication adherence } & \multicolumn{2}{|c|}{ Blood pressure controlled ${ }^{a}$} & \multirow[t]{2}{*}{$P$-value ${ }^{b}$} & \multirow[t]{2}{*}{ P-trend" } \\
\hline & No & Yes & & \\
\hline Adherence & $78(42.9 \%)$ & $104(57.1 \%)$ & 0.751 & 0.466 \\
\hline Unintentional nonadherence & 47 (43.9\%) & $60(56.1 \%)$ & & \\
\hline Intentional nonadherence & $53(47.3 \%)$ & $59(52.7 \%)$ & & \\
\hline
\end{tabular}

Notes: Values are presented as $\mathrm{n}(\%)$ unless otherwise indicated. aSystolic blood pressure $<140 \mathrm{mmHg}$ and diastolic blood pressure $<90 \mathrm{mmHg}$; ${ }^{\circ}$ chi-square test; 'chi-square test for trend. 
Table 4 Health behaviors according to medication adherence

\begin{tabular}{|c|c|c|c|c|}
\hline \multirow[t]{3}{*}{ Medication adherence } & \multicolumn{4}{|l|}{ Health behavior ${ }^{a}$} \\
\hline & \multicolumn{2}{|l|}{ Male } & \multicolumn{2}{|l|}{ Female } \\
\hline & Regression coefficient ${ }^{b}$ & $P$-value & Regression coefficient ${ }^{\mathrm{b}}$ & $P$-value \\
\hline Adherence (reference) & - & - & - & - \\
\hline Unintentional nonadherence & -0.476 & 0.692 & -0.237 & 0.412 \\
\hline Intentional nonadherence & 0.126 & 0.824 & -1.399 & 0.036 \\
\hline
\end{tabular}

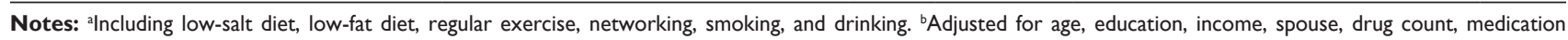
frequency, comorbidity, duration of hypertension, and self-rated health. The dash indicates no data.

may not be able to manage aversive situations successfully, even though they have enough knowledge and possess the requisite skills. ${ }^{18,36}$

Self-efficacy can be defined as a dynamic condition that can be reinforced through past experience of health behavior, but most hypertensive patients do not have any clinical symptoms and for this reason do not have immediate positive reward from taking the medicine. Most hypertensive patients do not present any immediate negative symptoms when not taken, nor does it cause any perceived negative consequences that may promote positive motives for medication adherence. Patients need to be aware of the long-term effect of medication, social and self-regulatory skills, and social supports. ${ }^{36}$ The patient-provider relationship is really important as other chronic disease ${ }^{35}$ and the unintentional nonadherence can be used as a marker of lower self-efficacy. In contrast to findings of the present study, some investigators have suggested that, in addition to necessity, concern about adverse effects or medication abuse relates to both intentional and unintentional nonadherence. ${ }^{13,31}$ It may be that the present study did not demonstrate an important effect of concern because the participants were elderly, with long-standing disease. If they had a lot of experience taking medication of any type, concern may have been less of a factor in adherence than necessity and self-efficacy.

The issue of intentional nonadherence tends to be too frequently ignored by health care professionals. ${ }^{37}$ Many general practitioners admit that they would like to help their patients with this issue but are unable to do so. ${ }^{38}$ In addition, interventions that are acknowledged to be effective may be difficult to implement because of the time and cost involved. ${ }^{39}$ Interventions for unintentional nonadherence, such as someone helping the patient take the medicine or sending text messages, were found to be easier to implement. ${ }^{37}$ However, the present study result suggests that beliefs about medication affect both intentional and unintentional nonadherence;

Table 5 Multiple regression of BMQ and self-efficacy

\begin{tabular}{|c|c|c|c|c|c|c|c|c|c|}
\hline \multirow[t]{3}{*}{ Predisposing factors } & \multicolumn{3}{|c|}{ Necessity } & \multicolumn{3}{|c|}{ Concerns } & \multicolumn{3}{|c|}{ Self-efficacy } \\
\hline & \multicolumn{2}{|c|}{$\begin{array}{l}\text { Unstandardized } \\
\text { coefficients }\end{array}$} & \multirow[t]{2}{*}{$P$-value } & \multicolumn{2}{|c|}{$\begin{array}{l}\text { Unstandardized } \\
\text { coefficients }\end{array}$} & \multirow[t]{2}{*}{ P-value } & \multicolumn{2}{|c|}{$\begin{array}{l}\text { Unstandardized } \\
\text { coefficients }\end{array}$} & \multirow[t]{2}{*}{$P$-value } \\
\hline & B & SE & & B & SE & & B & SE & \\
\hline Age (years) & -0.028 & 0.026 & 0.279 & -0.030 & 0.022 & 0.166 & 0.005 & 0.057 & 0.926 \\
\hline Gender (female/male) & 0.532 & 0.517 & 0.304 & 0.275 & 0.442 & 0.533 & 0.944 & 1.149 & 0.412 \\
\hline \multicolumn{10}{|c|}{ Educational level (reference: $\leq$ primary school) } \\
\hline Middle school & 0.454 & 0.706 & 0.520 & -0.729 & 0.604 & 0.228 & 0.128 & 1.570 & 0.935 \\
\hline$\geq$ High school & -0.814 & 0.941 & 0.388 & 0.270 & 0.805 & 0.738 & 1.980 & 2.093 & 0.345 \\
\hline \multicolumn{10}{|l|}{ Income (reference: $<$ I million KRW) } \\
\hline $\mathrm{I}-2$ million $\mathrm{KRW}$ & 0.433 & 0.640 & 0.499 & 1.087 & 0.548 & 0.048 & -2.586 & 1.424 & 0.070 \\
\hline$\geq 2$ million $\mathrm{KRW}$ & -0.938 & 0.998 & 0.348 & 0.133 & 0.854 & 0.876 & -1.409 & 2.220 & 0.526 \\
\hline Spouse (yes/no) & 0.231 & 0.440 & 0.600 & -0.073 & 0.376 & 0.846 & -0.040 & 0.978 & 0.967 \\
\hline Duration & 0.044 & 0.028 & 0.114 & 0.035 & 0.024 & 0.145 & 0.066 & 0.062 & 0.286 \\
\hline Drug count & 0.149 & 0.105 & 0.159 & 0.076 & 0.090 & 0.399 & 0.105 & 0.234 & 0.655 \\
\hline Medication frequency (twice/once) & 0.851 & 0.718 & 0.236 & 0.528 & 0.614 & 0.390 & -1.502 & 1.596 & 0.347 \\
\hline Comorbidity (yes/no) & 0.176 & 0.424 & 0.678 & -0.304 & 0.363 & 0.402 & 0.542 & 0.944 & 0.566 \\
\hline \multicolumn{10}{|l|}{ Self-rated health (reference: good) } \\
\hline Moderate & 0.298 & 0.618 & 0.630 & -0.253 & 0.528 & 0.632 & $-1.09 \mid$ & 1.374 & 0.428 \\
\hline Bad & $0.64 I$ & 0.639 & 0.317 & -0.400 & 0.546 & 0.464 & -0.934 & 1.421 & $0.5 \mathrm{II}$ \\
\hline
\end{tabular}

Note: Regression coefficients are presented as n (\%) unless otherwise indicated.

Abbreviations: BMQ, beliefs about medicines questionnaire; SE, standard error; KRW, Korean Won. 


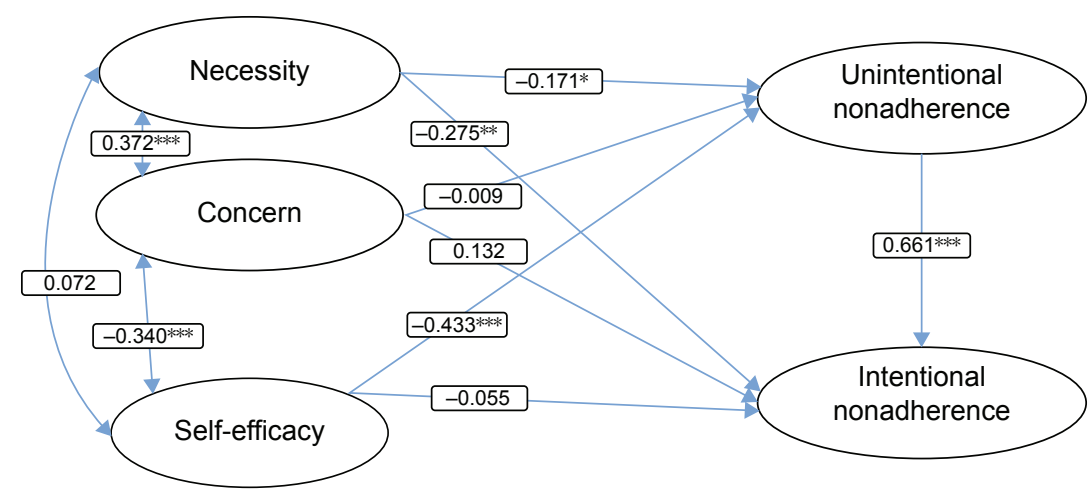

Figure 3 Standardized coefficients of structural equation model.

Notes: $\chi^{2}=122.644, \mathrm{GFI}=0.998, \mathrm{AGFI}=0.997, \mathrm{TLI}=0.972, \mathrm{CFI}=0.903, \mathrm{WRMR}=0.775$ and $\mathrm{RMSEA}=0.045, * P<0.05, * * P<0.0 \mathrm{I}, * * * P<0.00 \mathrm{I}$.

Abbreviations: AGFI, adjusted goodness of fit index; CFI, comparative fit index; GFI, goodness of fit index; RMSEA, root mean square error of approximation; TLI, TuckerLewis index; WRMR, weighted root mean square residual.

hence, interventions that do not address patients' beliefs may not be effective. ${ }^{13}$

Adherence, as measured by questionnaire, has been shown to be related to blood pressure control, ${ }^{29}$ but this was not found in the present study. Although patients in the nonadherence groups sometimes did not take their medicine, it is conceivable that they did take it on the day of survey, which may have acutely affected their blood pressure. The cross-sectional design has some limitations in investigating the relationship between adherence to medication and blood pressure control. However, systolic blood pressure in the intentional nonadherence group was higher than that in the other two groups, suggesting that there may be a relationship. Other studies should be designed to allow better assessment of the usual blood pressure, for example, measuring it for 24 hours or sequentially over a certain period of time.

In the present study, there was a negative association between intentional nonadherence and healthy behaviors only among women participants. This may illustrate the "healthy adherer effect", in which patients who are adherent to their

Table 6 Indirect effects of BMQ and self-efficacy on intentional nonadherence

\begin{tabular}{llc}
\hline Path & Indirect & Total \\
\hline $\begin{array}{l}\text { Necessity } \rightarrow \text { Unintentional nonadherence } \rightarrow \\
\text { Intentional nonadherence }\end{array}$ & $-0.113^{*}$ & -0.388 \\
$\begin{array}{l}\text { Concern } \rightarrow \text { Unintentional nonadherence } \rightarrow \\
\text { Intentional nonadherence }\end{array}$ & -0.006 & 0.126 \\
$\begin{array}{l}\text { Self-efficacy } \rightarrow \text { Unintentional } \\
\text { nonadherence } \rightarrow \text { Intentional nonadherence }\end{array}$ & $-0.286 * *$ & -0.34 I \\
\hline
\end{tabular}

Notes: $\chi^{2}=122.644, \mathrm{GFI}=0.998, \mathrm{AGFI}=0.997, \mathrm{TLI}=0.972, \mathrm{CFI}=0.903$, WRMR $=0.775$, and RMSEA $=0.045$. All regression coefficients are standardized, $* P<0.05, * * P<0.01$.

Abbreviations: BMQ, beliefs about medicines questionnaire; AGFI, adjusted goodness of fit index; CFI, comparative fit index; GFI, goodness of fit index; RMSEA, root mean square error of approximation; TLI, Tucker-Lewis index; WRMR, weighted root mean square residual. prescribed medications are also more likely to have healthy behaviors. ${ }^{2}$ The association between healthy behaviors, that is, lifestyle factors, and medication adherence should be further studied.

This study has several limitations. Beliefs about medicines and self-efficacy are both dynamic traits and those, which could be affected by feedback, from individual medication experiences. However, such changes over time cannot be examined in a cross-sectional design. The mediation effect of unintentional nonadherence also needs to be evaluated longitudinally in a cohort study. Cronbach's alpha value was 0.563 in our intentional nonadherence survey measure, but with same measure in community using randomized sampling method for stroke and hypertensive patient study showed 0.722 and 0.781 with acceptable reliability. ${ }^{7,40}$ Although adherence to medication is known to be related to comorbidity, drug count, or dosing frequency, ${ }^{7,24,41}$ the present survey did not assess the type of comorbid disease or the number of hypertensive drugs each participant took; hence, these factors could not be analyzed. In addition, it was not known when the blood pressure was measured in relation to the time the subject may have taken their medication. This issue should be considered in the design of future studies.

This study was performed to examine medicationtaking behaviors, including unintentional and intentional nonadherence, and related factors in elderly patients with hypertension. The results show the effects of necessity, concern, and self-efficacy on the two types of nonadherence, demonstrating the interrelationship of the two types of nonadherent behavior.

\section{Conclusion}

Unintentional nonadherence can easily be regarded as accidental, as opposed to the active nature of intentional nonadherence. 
However, the value of recognizing unintentional behavior lies in its potential prognostic significance. Unintentional nonadherence should be regularly monitored and managed. Interventions addressing cognitive factors, such as beliefs about medicine or self-efficacy, are relatively difficult to implement, but are essential to improve medication adherence.

\section{Disclosure}

The authors report no conflicts of interest in this work.

\section{References}

1. James PA, Oparil S, Carter BL, et al. 2014 evidence-based guideline for the management of high blood pressure in adults: report from the panel members appointed to the Eighth Joint National Committee (JNC 8). JAMA. 2014;311(5):507-520.

2. Simpson SH, Eurich DT, Majumdar SR, et al. A meta-analysis of the association between adherence to drug therapy and mortality. BMJ. 2006;333(7557): 15 .

3. Dimatteo MR, Giordani PJ, Lepper HS, Croghan TW. Patient adherence and medical treatment outcomes: a meta-analysis. Med Care. 2002;40(9):794-811.

4. Yang BG. 2013 Health Behavior and Chronic Disease Statistics. cheongju, Korea: Center for Disease Control and Prevention; 2014.

5. Sabaté E. Adherence to Long-Term Therapies: Evidence for Action. Geneva, Switzerland: World Health Organization; 2003.

6. Knight EL, Bohn RL, Wang PS, Glynn RJ, Mogun H, Avorn J. Predictors of uncontrolled hypertension in ambulatory patients. Hypertension. 2001;38(4):809-814.

7. Bae SG, Jeon HJ, Yang HS, Kim BK, Park KS. Medication adherence and its predictors in community elderly patients with hypertension. Korean J Health Promot. 2015;15(3):121-128.

8. Hugtenburg JG, Timmers L, Elders PJ, Vervloet M, van Dijk L. Definitions, variants, and causes of nonadherence with medication: a challenge for tailored interventions. Patient prefer Adherence. 2013; (7):675-682.

9. Lehane E, McCarthy G. Intentional and unintentional medication non-adherence: a comprehensive framework for clinical research and practice? a discussion paper. Int J Nurs Stud. 2007;44(8):1468-1477.

10. Al-Qazaz HK, Hassali MA, Shafie AA, Sulaiman SA, Sundram S, Morisky DE. The eight-item Morisky Medication Adherence Scale MMAS: translation and validation of the Malaysian version. Diabetes Res Clin Pract. 2010;90(2):216-221.

11. Lowry KP, Dudley TK, Oddone EZ, Bosworth HB. Intentional and unintentional nonadherence to antihypertensive medication. Ann Pharmacother. 2005;39(7-8):1198-1203.

12. Wroe AL. Intentional and unintentional nonadherence: a study of decision making. J Behav Med. 2002;25(4):355-372.

13. Gadkari AS, McHorney CA. Unintentional non-adherence to chronic prescription medications: how unintentional is it really? BMC Health Serv Res. 2012;12(1):98.

14. Rees G, Leong O, Crowston JG, Lamoureux EL. Intentional and unintentional nonadherence to ocular hypotensive treatment in patients with glaucoma. Ophthalmology. 2010;117(5):903-908.

15. Leventhal H, Leventhal EA, Contrada RJ. Self-regulation, health, and behavior: a perceptual-cognitive approach. Psychol Health. 1998; 13(4):717-733.

16. Horne R, Weinman J, Hankins M. The beliefs about medicines questionnaire: the development and evaluation of a new method for assessing the cognitive representation of medication. Psychol health. 1999;14(1):1-24.

17. Horne R, Chapman SC, Parham R, Freemantle N, Forbes A, Cooper V. Understanding patients' adherence-related beliefs about medicines prescribed for long-term conditions: a meta-analytic review of the Necessity-Concerns Framework. PLoS One. 2013;8(12):e80633.
18. Bandura A. Perceived self-efficacy in cognitive development and functioning. Educ Psychol. 1993;28(2):117-148.

19. Schoenthaler A, Ogedegbe G, Allegrante JP. Self-efficacy mediates the relationship between depressive symptoms and medication adherence among hypertensive African Americans. Health Educ Behav. 2009;36(1):127-137.

20. Nakahara R, Yoshiuchi K, Kumano H, Hara Y, Suematsu H, Kuboki T. Prospective study on influence of psychosocial factors on glycemic control in Japanese patients with type 2 diabetes. Psychosomatics. 2006;47(3):240-246.

21. Eliasson L, Clifford S, Barber N, Marin D. Exploring chronic myeloid leukemia patients' reasons for not adhering to the oral anticancer drug imatinib as prescribed. Leuk Res. 2011;35(5):626-630.

22. Raynor DK, Savage I, Knapp P, Henley J. We are the experts: people with asthma talk about their medicine information needs. Patient Educ Couns. 2004;53(2):167-174.

23. Conrad P. The meaning of medications: another look at compliance. Soc Sci Med. 1985;20(1):29-37.

24. Lee JK. Factors associated with drug misuse behaviors among polypharmacy elderly. Korean J Adult Nurs. 2011;23(6):554-563.

25. Jung JH, Kim YH, Han DJ, Kim KS, Chu SH. Kidney transplant recipients, immunosuppressants, medication adherence. J Korean Soc Tranplant. 2010;24(4):289-297.

26. Fernandez S, Chaplin W, Schoenthaler AM, Ogedegbe G. Revision and validation of the medication adherence self-efficacy scale (MASES) in hypertensive African Americans. J Behav Med. 2008;31(6):453-462.

27. Markus KA. Principles and Practice of Structural Equation Modeling by Rex B. Kline. Structural Equation Modeling: A Multidisciplinary Journal. 2012;19(3):509-512.

28. Yu C. Evaluation Cutoff Criteria of Model Fit Indices for Latent Variable Models with Binary and Continuous Outcomes [dissertation]. Accra: University of California Los Angeles; 2002.

29. Morisky DE, Ang A, Krousel-Wood M, Ward HJ. Predictive validity of a medication adherence measure in an outpatient setting. $J$ Clin Hypertens. 2008;10(5):348-354.

30. Osterberg L, Blaschke T. Adherence to medication. $N$ Engl J Med. 2005;353(5):487-497.

31. Unni EJ, Farris KB. Unintentional non-adherence and belief in medicines in older adults. Patient Educ Couns. 2011;83(2):265-268.

32. Atkins L, Fallowfield L. Intentional and non-intentional non-adherence to medication amongst breast cancer patients. Eur J Cancer. 2006; 42(14):2271-2276.

33. Leventhal H, Weinman J, Leventhal EA, Phillips LA. Health psychology: the search for pathways between behavior and health. Annu Rev Psychol. 2008;59:477-505.

34. Molloy GJ, Randall G, Wikman A, Perkins-Porras L, Messerli-Burgy N, Steptoe A. Type D personality, self-efficacy, and medication adherence following an acute coronary syndrome. Psychosom Med. 2012;74(1): 100-106.

35. Johnson MO, Chesney MA, Goldstein RB, et al. Positive provider interactions, adherence self-efficacy, and adherence to antiretroviral medications among HIV-infected adults: a mediation model. AIDS Patient Care STDs. 2006;20(4):258-268.

36. Bandura A. Perceived self-efficacy in the exercise of control over AIDS infection. Eval Program Plann. 1990;13:9-17.

37. Mukhtar O, Weinman J, Jackson SH. Intentional non-adherence to medications by older adults. Drugs Aging. 2014;31(3):149-157.

38. Persaud R. Both sides need to keep the relationship going. BMJ. 2003;326(7402):1337.

39. Elliott R. Non-adherence to medicines: not solved but solvable. J Health Serv Res Policy. 2009;14(1):58-61.

40. Kim YT, Park KS, Bae SG. Predictors of persistence and adherence with secondary preventive medication in stroke patients. $J$ Agric Med Community Health. 2015;40(1):9-20.

41. Barat I, Andreasen F, Damsgaard EMS. Drug therapy in the elderly: what doctors believe and patients actually do. Br J Clin Pharmacol. 2001;51(6):615-622. 
Patient Preference and Adherence

Dovepress

\section{Publish your work in this journal}

Patient Preference and Adherence is an international, peer-reviewed, open access journal that focuses on the growing importance of patient preference and adherence throughout the therapeutic continuum. Patient satisfaction, acceptability, quality of life, compliance, persistence and their role in developing new therapeutic modalities and compounds to optimize

Submit your manuscript here: http://www.dovepress.com/patient-preference-and-adherence-journ clinical outcomes for existing disease states are major areas of interest for the journal. This journal has been accepted for indexing on PubMed Central The manuscript management system is completely online and includes a very quick and fair peer-review system, which is all easy to use. Visit http://www. dovepress.com/testimonials.php to read real quotes from published authors. 